San Jose State University

SJSU ScholarWorks

Master's Theses

Master's Theses and Graduate Research

Summer 2019

\title{
An Investigation of the Effects of Individual Differences on Technology Acceptance in the Workplace
}

Robert Neil Payne

San Jose State University

Follow this and additional works at: https://scholarworks.sjsu.edu/etd_theses

\section{Recommended Citation}

Payne, Robert Neil, "An Investigation of the Effects of Individual Differences on Technology Acceptance in the Workplace" (2019). Master's Theses. 5041.

DOI: https://doi.org/10.31979/etd.q2re-cerx

https://scholarworks.sjsu.edu/etd_theses/5041

This Thesis is brought to you for free and open access by the Master's Theses and Graduate Research at SJSU ScholarWorks. It has been accepted for inclusion in Master's Theses by an authorized administrator of SJSU ScholarWorks. For more information, please contact scholarworks@sjsu.edu. 


\title{
AN INVESTIGATION OF THE EFFECTS OF INDIVIDUAL DIFFERENCES ON TECHNOLOGY ACCEPTANCE IN THE WORKPLACE
}

\author{
A Thesis \\ Presented to \\ The Faculty of the Department of Psychology \\ San José State University \\ In Partial Fulfillment \\ of the Requirements for the Degree \\ Master of Science
}

by

Rob Payne

August 2019 
(C) 2019

Rob Payne

ALL RIGHTS RESERVED 
The Designated Thesis Committee Approves the Thesis Titled

AN INVESTIGATION OF THE EFFECTS OF INDIVIDUAL DIFFERENCES ON TECHNOLOGY ACCEPTANCE IN THE WORKPLACE

by

Rob Payne

APPROVED FOR THE DEPARTMENT OF PSYCHOLOGY

SAN JOSÉ STATE UNIVERSITY

August 2019

Dr. Altovise Rogers

Dr. David Schuster

Dr. Daryl Hagan
Department of Psychology

Department of Psychology

Superintendent, Catholic Diocese of Evansville 


\title{
ABSTRACT \\ AN INVESTIGATION OF THE EFFECTS OF INDIVIDUAL DIFFERENCES ON TECHNOLOGY ACCEPTANCE IN THE WORKPLACE
}

\author{
by Rob Payne
}

The purpose of the current study was to test for moderating effects that conscientiousness, agreeableness, and openness to experience have on relationships in the technology acceptance model. More specifically, the current study tested for previously overlooked moderation effects that these personality traits have on the relationships between behavioral intention and its predictors (i.e. perceived ease of use, perceived usefulness, and subjective norms). A sample of 96 employees from more than 16 industries participated in the study by completing an online survey. Results of the current study displayed a significant moderation effect by agreeableness on the relationship between perceived ease of use and behavioral intention, such that the relationship was stronger for those low in agreeableness. Additionally, openness to experience was found to moderate the relationship between subjective norms and behavioral intention when controlling for time of familiarity, such that the relationship was stronger for those high in openness to experience. The theoretical and practical implications of these findings are discussed. 


\section{ACKNOWLEDGMENTS}

I would like to thank my thesis chair, Dr. Altovise Rogers, for being both supportive and resourceful at each phase of the thesis process. Her dedication to helping me achieve my goals is something I will appreciate for years to come. I would like to thank Dr. David Schuster for his thought-provoking feedback and for his willingness to join my thesis committee despite balancing a number of other academic responsibilities. I would also like to thank my third reader and former superintendent, Dr. Daryl Hagan, for his commitment to this project and for his seemingly endless contribution to my education. Aside from my thesis committee, I would like to thank my friends and family for all that they do, and especially for the support they have shown me throughout this process.

Lastly, I would like to thank my professors and fellow classmates from the I/O Psychology program at San Jose State University for pushing me and for providing me with the knowledge needed to pursue the next steps in my professional career confidently. 


\section{TABLE OF CONTENTS}

List of Tables.................................................................. viii

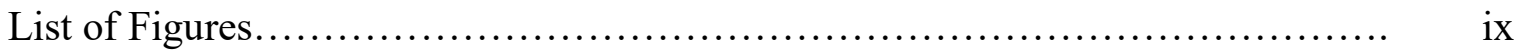

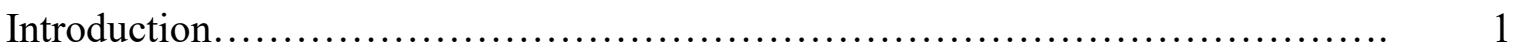

Introduction to the TAM................................................... 2

The Theory of Reasoned Action........................................... 2

Development of the TAM................................................... 4

Five-Factor Model of Personality.......................................... 6

Personality and the TAM................................................ 8

Current Study ....................................................... 11

Methods....................................................................... 14

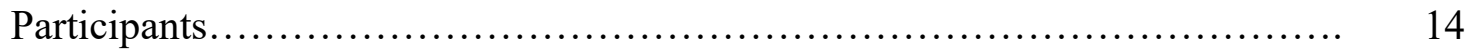

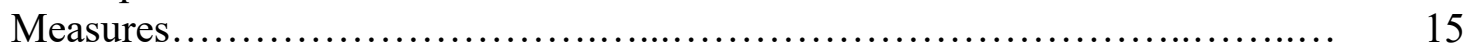

Technology acceptance............................................ 16

Perceived usefulness............................................. 16

Perceived ease of use .............................................. 17

Subjective norms............................................... 17

Behavioral intention................................................. 17

Personality ......................................................... 18

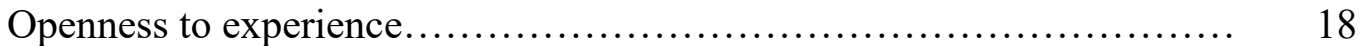

Agreeableness...................................................... 19

Conscientiousness..................................................... 19

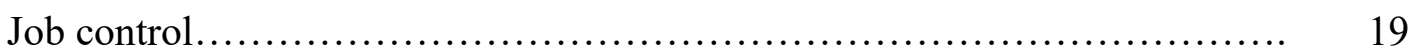

Procedure ............................................................. 20

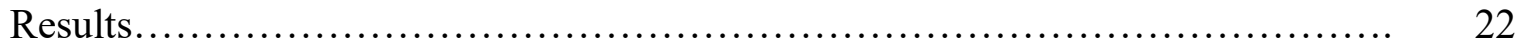

Descriptive Statistics............................................... 22

Correlations............................................................. 23

Tests of Hypotheses...................................................... 25

Control Variables........................................................... 28

Discussion........................................................................ 30

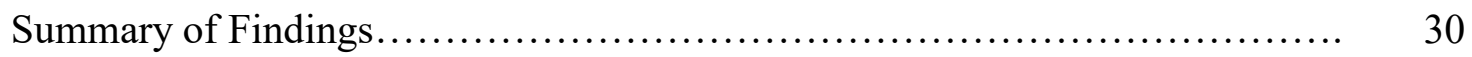

Theoretical Implications................................................ 31

Practical Implications.................................................. 33

Strengths and Limitations.................................................. 34

Strengths.............................................................. 34

Limitations......................................................... 35 
Suggestions for Future Research..................................... 36

Conclusion......................................................... 37

References............................................................ 38

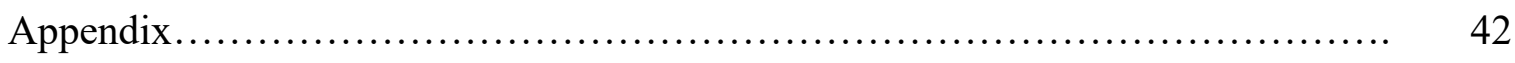




\section{LIST OF TABLES}

Table 1. Descriptive Statistics for TAM and Personality Variables.............. 22

Table 2. Pearson Correlations Between Variables............................... 24 


\section{LIST OF FIGURES}

Figure 1. Theory of reasoned action.................................. 3

Figure 2. Technology acceptance model.................................. 5

Figure 3. Research model............................................. 6

Figure 4. Moderation effect of agreeableness on the relationship between perceived ease of use and behavioral intention.................... 


\section{Introduction}

The rapid development of computer technology in the information age has placed greater importance on business software and the virtual workplace. Because of this, understanding the acceptance of technology by employees has become a topic of interest for organizations that have implemented information technology (IT) in the workplace. This interest led Davis (1986) to theorize the technology acceptance model (TAM), which seeks to relate the different psychological constructs that determine an individual's acceptance and use of new technologies. More recently, researchers have become interested in how personality traits relate to the model (Devaraj, Easley, \& Crant, 2008). However, existing studies have not tested for all potential moderators that the literature suggests would affect TAM relationships. Therefore, the goal of the present study is to address the research gaps left by past studies by examining the potential moderating effects that conscientiousness, agreeableness, and openness to experience might have on the relationships between perceptions that one possesses about a new workplace technology (i.e. perceived ease of use, perceived usefulness, and subjective norms) and behavioral intention to use this technology.

In the sections that follow this introduction, a number of topics will be discussed. First, there will be an overview of the TAM's relevance to modern organizations and the history behind the model's development, followed by a brief overview about the history of the Five-Factor Model (five-factor model) of personality traits. Then, a discussion about the relevant literature on the relationships between five-factor model personality traits and the TAM will be presented to convey what is known in relation to the current 
study's research topic. Lastly, the introduction will conclude with an overview of the purpose, goals, and hypotheses for the current study, as well as a theoretical rationale behind the hypotheses to be tested.

\section{Introduction to the TAM}

While the original TAM was developed three decades prior to the current study, the model remains relevant in organizational research. A main driver for its relevance is the TAM's specific focus on the acceptance of IT (Sharp, 2007). Scientific knowledge of factors that relate to an employee's decision to adopt IT has grown since the introduction of cloud computing in the early 2000s, and this introduction opened new doors for the IT industry, such as the ability for technology companies to offer software as a service. With the ever-increasing availability of cloud-based business services, companies that continue to devote resources to IT implementation stand to suffer great losses if employees are unwilling to adopt a new system. Thus, an organization's level of understanding of technology acceptance is likely to play a crucial role in success in the modern business environment.

\section{The Theory of Reasoned Action (TRA)}

Much of the original TAM (Davis, 1986) was based on Fishbein and Ajzen's (1975) theory of reasoned action (TRA), which was created to model the relationship between an individual's attitudes and behaviors. Aspects of this theory were incorporated into various versions of the TAM in the decades that followed. The full model for the theory of reasoned action can be seen in Figure 1. 


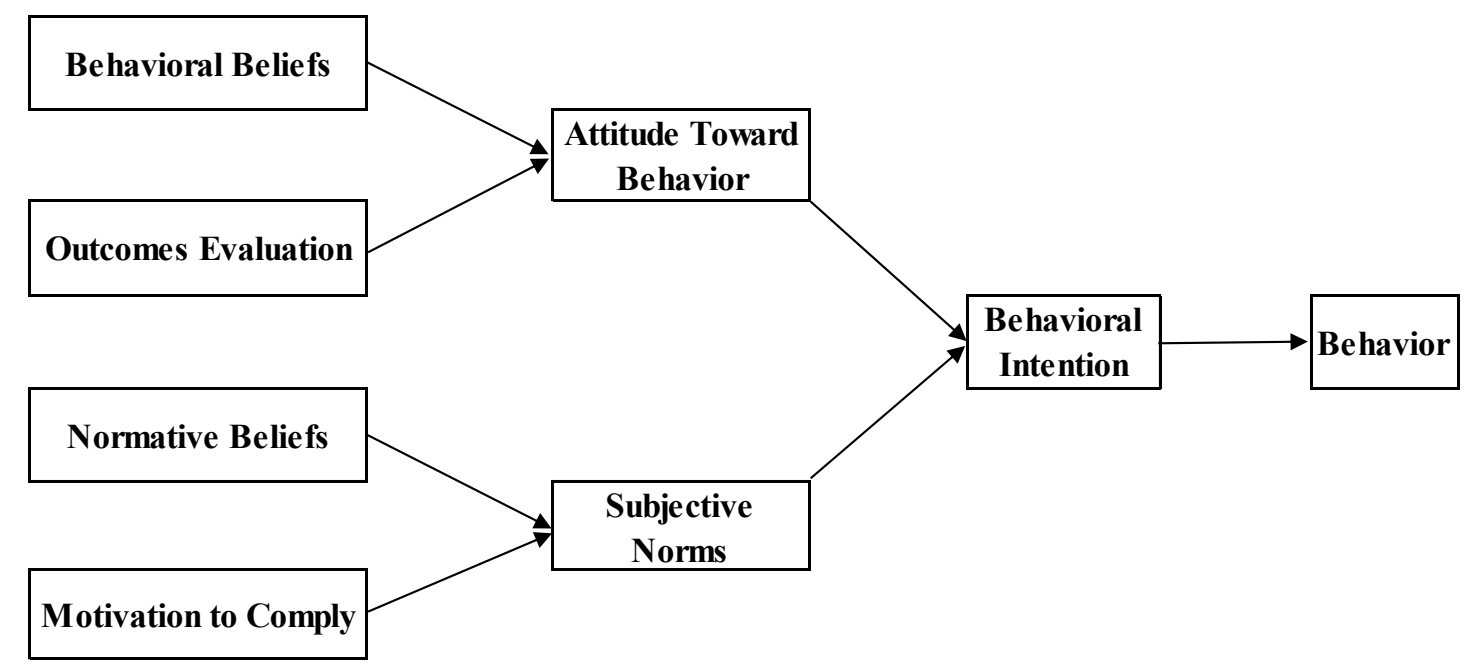

Figure 1. Theory of reasoned action. Adapted from Fishbein \& Ajzen (1975).

The TRA presumes that an individual's performance of a specific behavior is predicted by the behavioral intention to perform the behavior. Fishbein and Ajzen (1975) defined behavioral intention as "an individual's subjective probability that he or she will perform a specified behavior" (p. 288). Additionally, behavioral intention is determined by the combination of one's attitude toward a specific behavior and the subjective norms about that behavior. Fishbein and Ajzen (1975) defined subjective norms as "a person's perception that most people who are important to him think he should or should not perform the behavior in question" (p. 302), and the researchers found that subjective norms are determined by one's normative beliefs (i.e. perceptions about the expectations of others to perform the behavior) and one's motivation to comply with those expectations. 


\section{Development of the TAM}

Davis' (1986) original TAM was created in hopes of developing a theoretical model to represent the effects of system characteristics on users' adoption of information systems. More specifically, this model was focused on information systems used to support work activities at an employee's own discretion. Ultimately, the original TAM served as a preliminary model that has since been modified as subsequent research findings were uncovered.

In a study that led to the first modification of the TAM, Davis, Bagozzi, and Warshaw (1989) presented their model and outlined the ways in which the TAM relates to the TRA. As noted by the researchers, Fishbein and Ajzen (1975) created the TRA as a general model, meaning that using the model requires researchers to first identify the salient beliefs regarding the behavior being studied. Davis et al. (1989) conducted interviews with a sample of students to develop a set of salient beliefs in the context of technology acceptance, and these beliefs were determined to be the perceived usefulness and the perceived ease of use of the information system in question. Davis (1986) defined perceived usefulness as "the degree to which an individual believes that using a particular system would enhance his or her job performance" and perceived ease of use as "the degree to which an individual believes that using a particular system would be free of physical and mental effort” (p. 26). In line with the TRA, the TAM theorized that these behavioral beliefs predict one's attitude towards using a given system and that one's attitude towards use predicts behavioral intention (Davis et al., 1989). Additionally, the researchers proposed that behavioral intention was the lone predictor of usage behavior. 
In the same study, Davis et al. (1989) found results that would lead to further modifications to the TAM. The researchers found not only that attitude toward use had a non-significant effect on behavioral intention, but also that both perceived usefulness and perceived ease of use had significant direct effects on behavioral intention. With this knowledge, Davis et al. (1989) concluded that attitude towards use did not mediate the relationships between these perceptions and behavioral intention as well as originally hypothesized, leading to the exclusion of attitude towards use from the TAM in future studies (Sharp, 2007). The model that resulted from these findings can be seen in Figure 2.

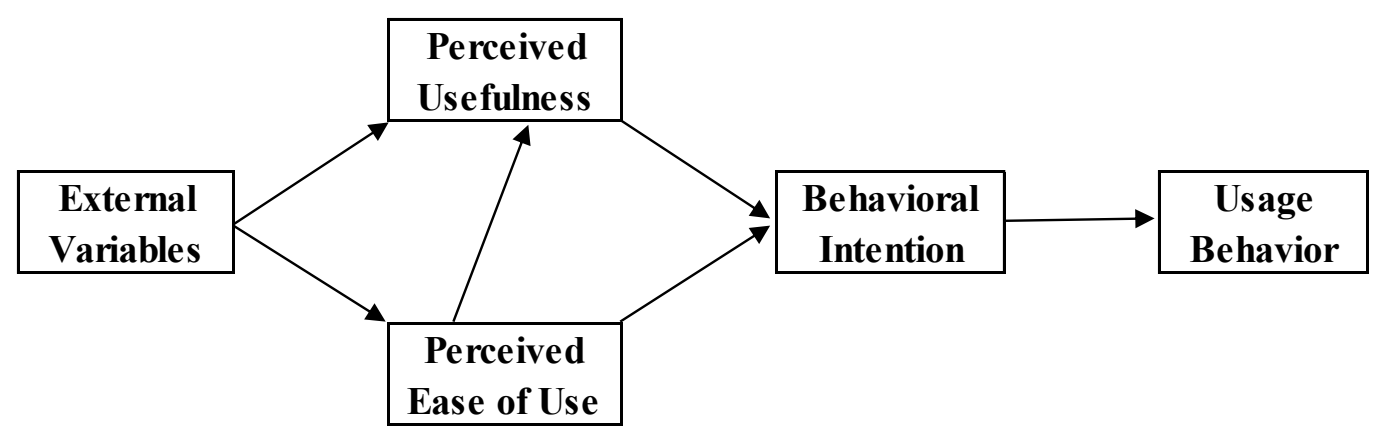

Figure 2. Technology acceptance model (Venkatesh \& Davis, 1996, p. 20).

A further modification to the TAM by Venkatesh and Davis (2000) led to the inclusion of subjective norms as a predictor of behavioral intention. In contrast to the TRA, the subjective norms construct was excluded from earlier versions of the TAM (see Figure $1 \&$ Figure 2). To rationalize this exclusion, Davis et al. (1989) noted the uncertain theoretical and psychometric status of the construct at the time the TAM was first developed. However, Venkatesh and Davis (2000) revisited the role of subjective norms in a longitudinal study on technology acceptance. The researchers determined 
subjective norms was a predictor of behavioral intention, as empirical findings from their study showed that individuals may perform a behavior, even if it is not seen as favorable, if the individual is motivated to comply with a salient referent that believes the behavior should be performed. Subjective norms have since been studied as a predictor of behavioral intention in a multitude of TAM-related studies (e.g. Devaraj et al., 2008), and the inclusion of subjective norms in this role has found further support through metaanalysis (Schepers \& Wetzels, 2007).

The TAM used in the current study includes perceived usefulness, perceived ease of use, and subjective norms as predictors of behavioral intention (see Figure 3). Additionally, in alignment with past versions of the TAM, perceived ease of use is proposed to have a direct effect on perceived usefulness in the current study.

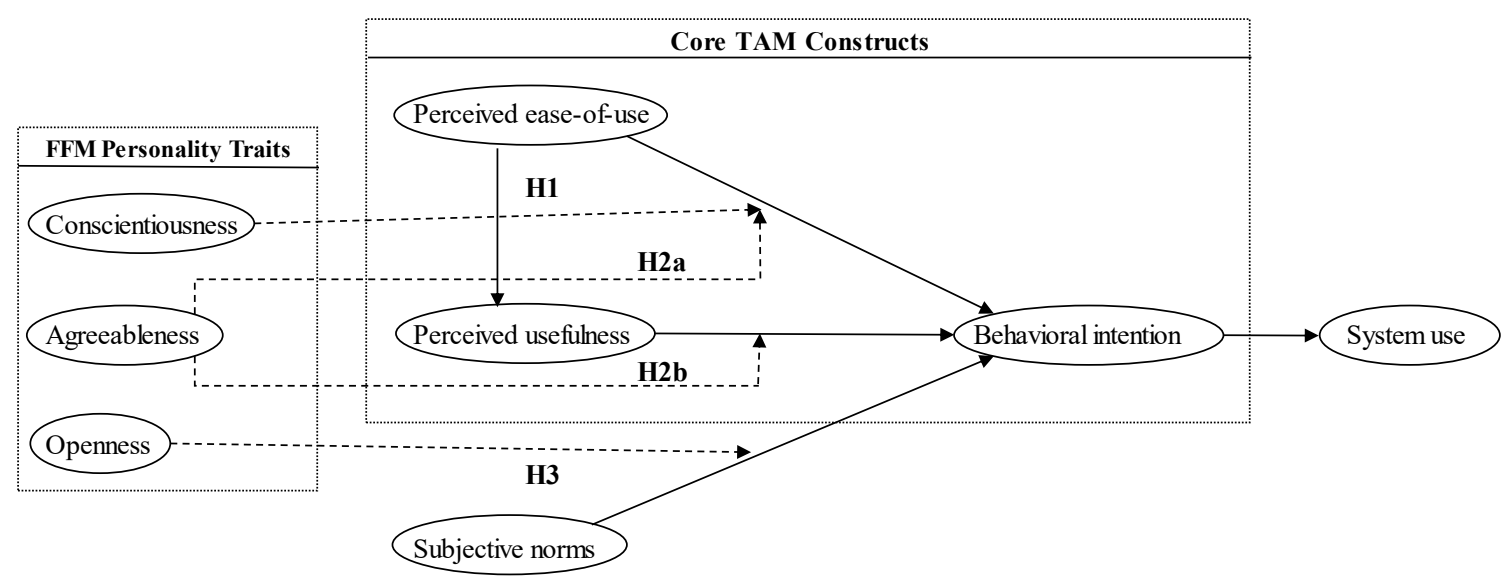

Figure 3. Research model.

Note. The current study's hypotheses are represented by dotted arrows

\section{Five-Factor Model of Personality}

Over the years, researchers have sought to understand the role of personality in determining technology acceptance. Personality traits have long been thought of as 
external factors that affect behavior indirectly through their influence on beliefs, attitudes, and intentions (Ajzen \& Fishbein, 1980). Thus, researchers have sought to understand the effects of personality on technology acceptance by studying the relationships between five-factor model personality traits and TAM constructs.

After years of being criticized for lacking a classification scheme for thousands of traits, personality psychologists have come to the agreement that one's personality can be condensed into five overarching factors: agreeableness, conscientiousness, extraversion, neuroticism, and openness to experience (Barrick, Mount, \& Judge, 2001). This set of broad categories has since been known as the five-factor model of personality, which is considered the most widely accepted classification system in the field of personality research. In creating this classification scheme, researchers have effectively developed a comprehensive taxonomy for studying personality. Consequently, the effects of these personality factors on decision-making processes has become a key point of interest in psychological research.

The personality traits of interest to the current study are conscientiousness, agreeableness, and openness to experience. As noted by Goldberg (1993) in his discussion of the five-factor model's development, each trait in the model represents a group of related sub-traits. Conscientiousness encompasses one's level of organization, thoroughness, and reliability, as well as contrasting traits such as carelessness, negligence, and unreliability. Agreeableness represents one's degree of kindness, trust, and warmth, as well as traits such as hostility, selfishness, and distrust. Lastly, openness 
to experience involves traits such as imagination, curiosity, and creativity and contrasts with traits such as shallowness and imperceptiveness.

While the personality traits of extraversion and neuroticism have been studied in relation to technology acceptance in the past (e.g., Devaraj et al., 2008), these traits have been left out of the current study due to the lack of empirical evidence suggesting moderating effects would be observed. Thus, the following section will outline the relevant literature on the relationships between conscientiousness, agreeableness, and openness to experience and TAM constructs.

\section{Personality and the TAM}

In a study that assessed the relationship between five-factor model traits and the acceptance of technical knowledge management systems, Sullivan (2012) hypothesized that conscientiousness, openness to experience, and agreeableness would possess positive relationships with perceived usefulness and perceived ease of use. The sample in this study consisted of consultants, researchers, employees, and managers that utilized these systems on a daily basis. Consistent with what was hypothesized, Sullivan (2012) found that openness to experience possessed a weakly positive relationship with perceived usefulness and a moderately positive relationship with perceived ease of use. However, in contrast to what was hypothesized, neither conscientiousness nor agreeableness were related to perceived usefulness or perceived ease of use.

In similarity with Sullivan (2012), Svendsen, Johnsen, Almas-Sorensen, and Vitterso (2013) also hypothesized that openness to experience would possess a positive relationship with perceived ease of use. In this study, the sample was comprised of 
Norwegian individuals over the age of 15 years. In support of the researchers' hypothesis, openness to experience was found to possess a weakly positive relationship with perceived ease of use. Additional findings from this study include the significant relationships between openness to experience and both subjective norms (weakly negative) and perceived usefulness (weakly positive). The analyses also displayed weakly positive relationships between agreeableness and behavioral intention, perceived usefulness, and perceived ease of use. Interestingly, the analyses showed that conscientiousness did not possess a significant relationship with any of the TAM constructs (i.e. behavioral intention, perceived usefulness, perceived ease of use, and subjective norms).

In a study about the acceptance of a commercial system for collaborative communication, Devaraj et al. (2008) formed a number of hypotheses about moderating effects that five-factor model traits may have on TAM relationships. In this study, the personality traits of MBA students were measured using items from the NEO-five-factor model (Costa \& McCrae, 1992). TAM constructs were measured using the instrument from Davis (1989), with the exception of subjective norms, which was measured using modified questions from Taylor and Todd's (1995) subjective norm of internet use measure. The researchers hypothesized that conscientiousness would moderate the individual relationships that perceived usefulness and subjective norms have with behavioral intention, such that these relationships would be stronger for those higher in conscientiousness. Additionally, Devaraj et al. (2008) hypothesized that agreeableness would moderate the relationship between subjective norms and behavioral intention, such 
that the relationship would be stronger for those higher in agreeableness. These hypotheses were tested using a structural equation modeling framework, which the researchers note was used to allow for simultaneous estimation of measurement and structural models.

Devaraj et al.'s (2008) hypotheses were supported in that conscientiousness moderated the relationship between perceived usefulness and behavioral intention, with the relationship being stronger for those higher in conscientiousness, conscientiousness moderated the relationship between subjective norms and behavioral intention, with the relationship being stronger for those higher in conscientiousness, and agreeableness moderated the relationship between subjective norms and behavioral intention, with the relationship being stronger for those higher in agreeableness.

In a study aimed at accounting for the effects of personality traits on the acceptance of web-enabled software, Behrenbruch, Sollner, Leimeister, and Schmidt (2013) hypothesized that openness to experience would moderate the relationships that both perceived usefulness and perceived ease of use possess with behavioral intention. In this study, personality traits and TAM constructs were measured in a sample of undergraduate business students. Personality traits were measured using questions from Gosling, Rentfrow, and Swann's (2003) measure of the Big-Five personality domains, and TAM constructs were measured with questions from the UTAUT (Venkatesh, Morris, Davis, \& Davis, 2003). In contrast to what was hypothesized, the researchers did not find a significant moderating effect by openness to experience on either of the relationships mentioned previously. 
While the findings from the aforementioned studies did advance the field's knowledge on the topic, research gaps were left regarding potential moderating effects of personality traits. Despite testing for moderating effects on certain TAM relationships, Devaraj et al. (2008) failed to test for the moderating effect that conscientiousness may have on the relationship between perceived ease of use and behavioral intention. Devaraj et al. (2008) also failed to test for moderating effects that agreeableness might have on the relationships that both perceived ease of use and perceived usefulness have with behavioral intention. Furthermore, Behrenbruch et al. (2013) failed to test for the moderating effect that openness to experience might have on the relationship between subjective norms and behavioral intention. These research gaps will be addressed in the current study.

\section{Current Study}

The purpose of the current study is to fill in the research gaps left by past studies by testing for moderating effects that conscientiousness, agreeableness, and openness to experience might have on TAM relationships. More specifically, this study will test for the moderating effects that previous studies did not, in hopes of providing a more complete understanding of how these personality traits impact one's acceptance of technology. To do this, the research model used in the current study will include all of the core TAM relationships (i.e. the relationships between perceived ease of use, perceived usefulness, and behavioral intention), as well as the direct relationship that subjective norms possess with behavioral intention (see Figure 3). 
Conscientious individuals display the tendencies to be thorough, organized, achievement-oriented, and persevering (Barrick \& Mount, 1991), and these tendencies are heavily linked to an employee's intrinsic motivation to improve job performance (Barrick et al., 2001). Because of this motivation to improve performance, as well as the tendency to display perseverance, highly conscientious individuals should place more importance on the overall utility of the technology, and less importance on the technology's ease of use when forming behavioral intentions. In contrast, the current study proposes that a lack of these tendencies would have the opposite effect on an employee's behavior, meaning employees with lower levels of conscientiousness will place more importance on the difficulty involved in using a new technology.

Hypothesis 1 (H1): Conscientiousness will moderate the relationship between perceived ease of use and behavioral intention, such that the relationship will be stronger for those lower in conscientiousness.

Agreeable individuals display the tendencies to be kind, gentle, trusting, and trustworthy (Barrick \& Mount, 1991). In work settings, having these tendencies often leads employees to be more cooperative when asked to adopt a new technology, which can be partially attributed to the relationship that agreeableness has with social influence (Devaraj et al., 2008). Because those who are highly agreeable are more prone to being influenced by the opinions of others, these individuals will likely place more importance on social factors such as subjective norms when deciding whether to adopt a new technology. Inversely, the current study speculates that individuals low in agreeableness 
will place more importance on non-social factors such as perceived ease of use and perceived usefulness when making decisions about adopting new technology.

Hypothesis 2a (H2a): Agreeableness will moderate the relationship between perceived ease of use and behavioral intention, such that the relationship will be stronger for those lower in agreeableness.

Hypothesis 2b (H2b): Agreeableness will moderate the relationship between perceived usefulness and behavioral intention, such that the relationship will be stronger for those lower in agreeableness.

People who are open to experience display the tendencies to be creative, nonconforming, and experimental (Barrick \& Mount, 1991). These individuals tend to actively seek out innovation and place greater value on change (McCrae \& Costa, 1997), and therefore, should be more likely to place importance on the overall utility of the technology. Because of this, individuals who are higher in openness to experience should be less likely to place importance on factors such as subjective norms when deciding whether to use a new technology. Thus, the current study posits that employees who are higher in openness to experience will be more willing to try new technologies in the workplace, even when there is no social pressure to do so.

Hypothesis 3 (H3): Openness to experience will moderate the relationship between subjective norms and behavioral intention, such that the relationship will be stronger for those lower in openness to experience. 


\section{Methods}

\section{Participants}

An initial set of participants was identified through the researcher's professional network using a convenience sampling method. An invitation to participate in the study was sent to prospective participants via email, and the invitation was also posted by the researcher on social media. Furthermore, a snowball sampling method was used to identify participants in the researcher's extended network. Once the survey was completed, participants were asked to send the invitation to others in their professional network. Additional participants were identified as the invitation posted by the researcher on social media was also re-posted by others in the researcher's network.

All participants in the current study were professionals that were currently employed by an organization. There were initially 124 participants surveyed, but 26 participants failed to complete items that were necessary to determine values for the variables that were key to testing the current study's hypotheses. Thus, the data for these participants were removed. Additionally, the data from another two participants were removed due to concerns about response bias, as these participants responded strongly in the affirmative for all items in the scale, including negatively worded items. Thus, further analyses were performed on a sample of 96 participants.

There were two criteria for inclusion in the sample. All participants were over the age of 18 and must use a computer in some capacity to perform their job. These criteria were set because the researcher was only interested in studying adults, and the technology acceptance measure in the survey would not apply to professionals who do not use a 
computer at work. Those who did not meet these criteria were not included in the current study. There were no incentives provided for participation in the study.

The sample was moderately representative of the target population. Participants consisted of mostly young adults, with $62.5 \%$ of the sample being in the age range of 18 24 years. The sample was split relatively evenly between gender groups, with $53.1 \%$ of participants being male and $45.8 \%$ being female. The sample consisted of employees in more than 16 different industries, with the consulting, technology, and healthcare industries making up a combined $53.2 \%$ of the total sample. A large majority of the sample was employed in a full-time work arrangement in their organization (84.4\%), while $15.6 \%$ of the sample was employed in a part-time work arrangement. The majority of the sample also indicated their use of the IT system at work was mandatory (59.4\%), with $40.6 \%$ of the sample indicating their use of the system was optional. The sample's time of familiarity with the IT system was relatively high, with $71.9 \%$ of participants being acquainted with the system for more than 6 months.

\section{Measures}

The survey used in the current study consisted of three primary measures: technology acceptance, personality, and job control. The measures for technology acceptance and personality consisted of multiple dimensions, and these dimensions are described further in the sections to follow. Cronbach's alpha $(\alpha)$ was used to calculate internal reliability for the job control measure and for each dimension within the technology acceptance and personality measures, and all analyses were performed using SPSS 24. 
Technology acceptance. The measure used by the researcher for the technology acceptance variables evaluated each participant's intention to use a specific information system available to them in their current job role, as well as the three predictors of this intention included in the current study's research model. Prior to completing the technology acceptance measure, participants were asked to identify an IT system that had been recently introduced to them at work. The item stated, "From the list provided, please select one system (i.e. computer program, business software, or web tool) that has been recently introduced to you at your current job. The system you select must be one that you have access to use. If the system you have in mind is not listed, select 'Other', and enter the name of the system in the text box provided." Each participant was presented with a list of 39 commonly-used IT systems, including multiple tools for collaboration and communication, customer relationship management, enterprise resource planning, and document management, among others. The selected IT system was then inserted into each item measuring perceived usefulness, perceived ease of use, subjective norms, and behavioral intention. Responses were based on a 7-point Likert-type scale in which participants indicated their level of agreement with each item $(1=$ Strongly disagree, $2=$ Disagree, $3=$ Somewhat disagree, $4=$ Neither agree nor disagree, $5=$ Somewhat agree, $6=$ Agree , and $7=$ Strongly agree $)$. The complete measure for technology acceptance can be seen in the Appendix. Further descriptions of the technology acceptance constructs measured in the current study are discussed in the sections to follow.

Perceived usefulness. The degree to which an individual believes that a particular system enhances his or her job performance was measured by three items. Items were 
adapted from Davis and Venkatesh's (1996) technology acceptance model for WordPerfect questionnaire. As Davis and Venkatesh's questionnaire was designed to measure technology acceptance in students using WordPerfect, items were predominantly adapted by replacing "WordPerfect" with the IT system selected by the participant and by replacing "in my degree program" with either "at work" or "in my job" (e.g. "Using (insert IT system) improves my productivity at work.").The item set for the perceived usefulness dimension was determined to possess good internal reliability, $\alpha=.84$.

Perceived ease of use. The degree to which an individual believes that using a particular system would be free of physical and mental effort was also measured by three items adapted from Davis and Venkatesh's (1996) scale (e.g. “Interacting with (insert IT system) does not require much of my mental effort."). The item set for the perceived usefulness dimension was determined to possess good internal reliability, $\alpha=.84$.

Subjective norms. Subjective norms were measured by three items adapted from Taylor and Todd's (1995) subjective norm of internet use measure. Items were predominantly adapted by replacing "Internet" with the IT system selected by each participant (e.g. "People who are important to me think that I should use (insert IT system)."). The item set for the subjective norms dimension was determined to possess good internal reliability, $\alpha=.86$.

Behavioral intention. An individual's subjective probability that he or she will use a specific system was measured by two items adapted from Davis and Venkatesh's (1996) scale (e.g. "Assuming I have access to (insert IT system), I intend to use it in the future."). 
The item set for the behavioral intention dimension displayed good internal reliability, $\alpha$ $=.89$.

Personality. The researcher's measure for personality traits consisted of eighteen total items from the IPIP-NEO-120 scale (Johnson, 2014). In this measure, openness to experience, agreeableness, and conscientiousness were measured by six items apiece. The decision to include six items for each personality trait was based on the IPIP-NEO-120's format, in which each trait is composed of six separate sub-traits, referred to as facets. While the IPIP-NEO-120 scale includes four items to measure each facet, the current study condensed this scale by utilizing one item for each facet. Participants indicated their level of agreement with each item on a 7 -point Likert-type scale $(1=$ Strongly disagree, $2=$ Disagree, $3=$ Somewhat disagree, $4=$ Neither agree nor disagree, $5=$ Somewhat agree, $6=$ Agree, and $7=$ Strongly agree). Nine of the 18 total items in this measure were negatively worded and were thus reverse-scored to emulate the IPIP-NEO120. All items in the personality measure can be seen in the Appendix. Further descriptions of the traits measured in the current study are discussed in the sections to follow.

Openness to experience. To reflect the IPIP-NEO-120, the six facets that comprised the openness to experience dimension were imagination, artistic interests, emotionality, adventurousness, intellect, and liberalism. As mentioned previously, each facet was evaluated by one item (e.g. imagination was measured with the statement, "I like to get lost in thought."). The internal reliability of the six-item set for the openness to experience dimension was unacceptable; however, the analysis showed that Cronbach's 
alpha would increase with the removal of certain items. Four items were removed from further analyses, but the internal reliability for the item set that remained was poor, $\alpha=$ .54 .

Agreeableness. The agreeableness dimension consisted of items reflecting the facets of trust, morality, altruism, cooperation, modesty, and sympathy (e.g. trust was measured with the statement, "I believe that others have good intentions."). The analysis showed that the reliability of the six-item set for this dimension was unacceptable; however, the removal of certain items would lead to a considerable increase in alpha for the item set, leading to the removal of four items from further analyses. Despite the increase in alpha, the internal reliability for the remaining item set was poor, $\alpha=.50$.

Conscientiousness. The conscientiousness dimension was measured by items representing self-efficacy, orderliness, dutifulness, achievement-striving, self-discipline, and cautiousness (e.g. self-efficacy was measured with the statement, "I excel in what I do.”). The analysis of reliability showed that removing certain items would lead to an increase in alpha for the item set for this dimension, leading to the removal of three items from further analyses. The set of three items that remained for conscientiousness displayed questionable internal reliability, $\alpha=.62$.

Job control. Job control refers to an employee's level of authority in making jobrelated decisions and autonomy in choosing which job skills to use at work (Karasek, 1979). Past research has found that job control was positively related to technology use (Richardson \& Thompson, 2012), therefore, job control was measured to ensure the 
variable did not impact responses to technology acceptance items as a confounding variable.

The researcher's measure for job control consisted of three items from Steptoe's (2001) job control measure (e.g. "I am responsible for deciding how much work gets done in my job."). For this measure, participants indicated their level of agreement on a 7-point Likert-type scale $(1=$ Strongly disagree, 2 = Disagree, $3=$ Somewhat disagree, 4 $=$ Neither agree nor disagree, $5=$ Somewhat agree, $6=$ Agree, and $7=$ Strongly agree) . The item set for job control was found to display good internal reliability, $\alpha=.81$. The items used in the job control measure can be seen in the Appendix.

\section{Procedure}

Surveys were administered online using Qualtrics. Each participant received an online invitation to take part in the study, which included a link to the study's consent notice. The consent notice explained that the study was related to technology acceptance, that participation in the study was voluntary, and that all responses would be kept anonymous.

Participants who indicated their consent were then asked to identify an IT system that had been recently introduced to them at their current job. The IT system identified must have been a system that the participant had access to use. Once identified, participants were asked to indicate their level of agreement with a series of statements that measured each participant's perceptions and attitudes towards the system. Participants were then asked to do the same for statements that measured personality traits and one's level of job 
control. Excluding outliers $(n=10)$ that were omitted using the IQR method (Seo, 2006), surveys were completed in approximately five minutes $(M=4.49 \mathrm{~min}, S D=1.29 \mathrm{~min})$. 


\section{Results}

\section{Descriptive Statistics}

Means and standard deviations of all scale variables can be seen in Table 1 . The sample rated the IT systems highly in perceived usefulness, with low levels of variability in ratings. The sample also rated the systems high in perceived ease of use, with variability being moderately low for this construct. Subjective norms towards the systems was rated highly, with moderately low levels of variability. The sample also displayed high levels of behavioral intention to use the systems with moderately low variability in ratings. The sample displayed high levels of openness to experience, but variability for this trait was low. The sample was moderately high in agreeableness, with moderately low levels of variability between participants. Participants were also moderately high in conscientiousness, and variability was low for this trait as well.

Table 1

Descriptive Statistics for TAM and Personality Variables

$N \quad$ Min $\quad$ Max $\quad M \quad S D$

Technology acceptance

Perceived usefulness

$\begin{array}{lllll}96 & 2.67 & 7.00 & 5.76 & 0.91\end{array}$

Perceived ease of use

$\begin{array}{lllll}96 & 2.00 & 7.00 & 5.54 & 1.15\end{array}$

Subjective norms

$\begin{array}{lllll}96 & 2.33 & 7.00 & 5.61 & 1.07\end{array}$

Behavioral intention

$\begin{array}{lllll}96 & 1.00 & 7.00 & 5.96 & 1.08\end{array}$

\section{Personality traits}

Openness

Agreeableness

Conscientiousness

$\begin{array}{lllll}96 & 3.00 & 7.00 & 5.59 & 0.91 \\ 96 & 3.00 & 7.00 & 5.41 & 1.01 \\ 96 & 3.00 & 7.00 & 5.09 & 0.96\end{array}$




\section{Correlations}

Pearson correlations were calculated to assess the strength of relationships between variables, and these correlation coefficients can be viewed in Table 2. Overall, technology acceptance variables were found to be highly correlated with each other. Perceived usefulness was found to share a moderately positive relationship with perceived ease of use, suggesting those who believed the identified IT system enhances job performance were more likely to believe using the system is free of effort. Perceived usefulness and subjective norms possessed a strongly positive relationship, suggesting respondents who believed the system enhances job performance were considerably more likely to believe most people who matter to them at work think the respondent should use the system. Perceived usefulness also shared a strongly positive relationship with behavioral intentions, suggesting those who believed the system enhances job performance were considerably more likely to believe they will use the system at work. Perceived ease of use displayed a moderately positive relationship with behavioral intention, suggesting those who believed using the system is free of effort were more likely to believe they will use the system at work. Subjective norms also displayed a moderately positive relationship with behavioral intention, suggesting respondents were more likely to believe they will use the system if others at work think the system should be used. 


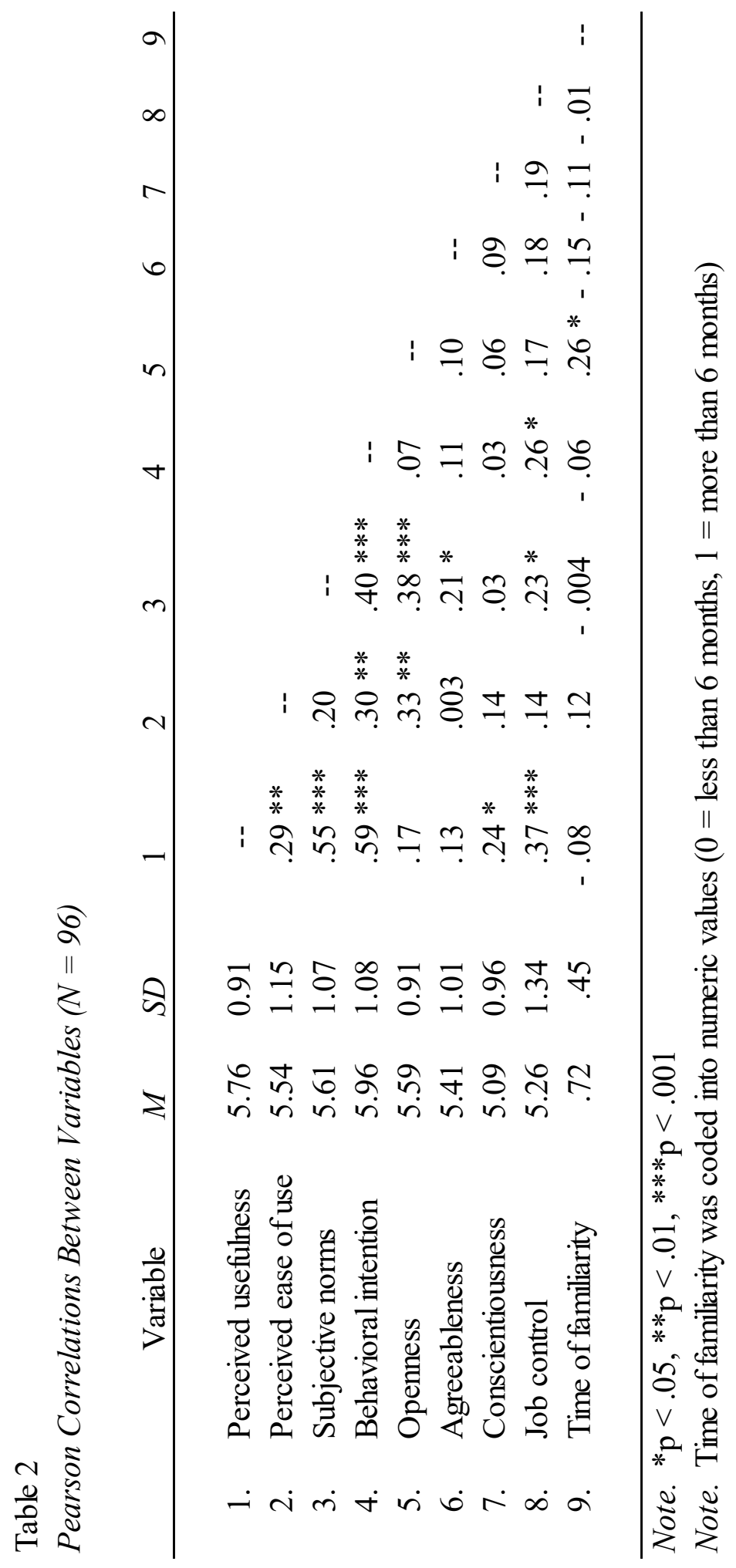


Overall, the analysis showed that the personality traits were weakly correlated with the technology acceptance constructs. Openness to experience shared moderately positive relationships with perceived ease of use and subjective norms. This suggests respondents who were open to experience were more likely to believe that using the system is free of effort and that those who are important to them at work think the respondent should use the system. Agreeableness was found to possess a weakly positive relationship with subjective norms, suggesting agreeable respondents were slightly more likely to believe people who matter to them at work think the respondent should use the system.

Conscientiousness shared weakly positive relationships with perceived usefulness, suggesting conscientious individuals were slightly more likely to believe using the system enhances job performance.

\section{Test of Hypotheses}

The current study hypothesized four separate moderation effects by personality traits on relationships from the technology acceptance model. To test these hypotheses, four moderated analyses were performed using hierarchical multiple regression in SPSS 24. In each regression model, behavioral intention served as the criterion, and independent variables were entered in two separate steps. A traditional predictor of behavioral intention (i.e. perceived ease of use, perceived usefulness, or subjective norms) and a moderator (i.e. conscientiousness, agreeableness, or openness to experience) were entered in the first step, and the interaction between the predictor and moderator was entered in the second step in each model. Further depictions of the analyses performed are detailed in the sections to follow. 
Hypothesis 1 stated that conscientiousness would moderate the relationship between perceived ease of use and behavioral intention, such that the relationship will be stronger for those lower in conscientiousness. The direct effects of perceived ease of use and conscientiousness on behavioral intention were assessed in the first step of the regression model. The analysis showed that perceived ease of use and conscientiousness, as a set, were related to behavioral intention, $R^{2}=.09, R_{a d j}^{2}=.07, F(2,93)=4.67, p<.05$. Of the two variables entered in this step, only perceived ease of use displayed a significant unique contribution to variance in behavioral intention, $b=0.29, t(95)=3.04, p<.01$. Results from the second step of the regression model were observed to determine the presence of a moderation effect. In contrast to what was hypothesized, there was no significant moderation effect by conscientiousness on the relationship between perceived ease of use and behavioral intention, $\Delta R^{2}=.007, F(1,92)=.75, p>.05$. Thus, the results provide no evidence that the relationship between perceived ease of use and behavioral intention changes at different levels of conscientiousness, and Hypothesis 1 was not supported.

Hypothesis 2a stated that agreeableness would moderate the relationship between perceived ease of use and behavioral intention, such that the relationship will be stronger for those lower in agreeableness. The first step in the regression model showed that perceived ease of use and agreeableness, as a set, were related to behavioral intention, $R^{2}$ $=.10, R_{a d j}^{2}=.08, F(2,93)=5.28, p<.01$. Of the variables entered in this step, only perceived ease of use displayed a significant unique contribution to variance in behavioral intention, $b=0.28, t(95)=3.07, p<.01$. Consistent with what was 
hypothesized, agreeableness was found to moderate the relationship between perceived ease of use and behavioral intention, $\Delta R^{2}=.04, F(1,92)=4.14, p<.05$. The results suggests the relationship between perceived ease of use and behavioral intention changes at different levels of agreeableness, such that the relationship was stronger for those lower in agreeableness, $R^{2}=.21, R_{a d j}^{2}=.19, F(1,51)=13.54, p<.01$ (see Figure 4). Thus, Hypothesis 2a was supported.

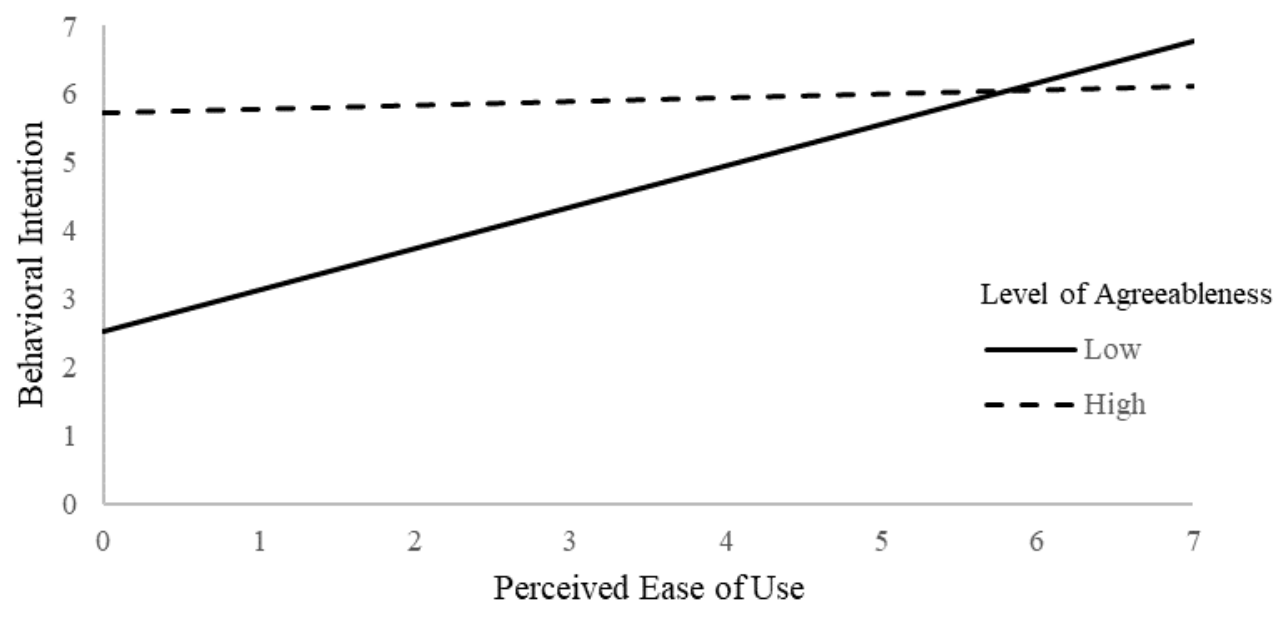

Figure 4. Moderation effect of agreeableness on the relationship between perceived ease of use and behavioral intention.

Hypothesis $2 \mathrm{~b}$ stated that agreeableness would moderate the relationship between perceived usefulness and behavioral intention, such that the relationship will be stronger for those lower in agreeableness. The first step in the regression model showed that perceived usefulness and agreeableness, as a set, were related to behavioral intention, $R^{2}$ $=.35, R_{a d j}^{2}=.34, F(2,93)=25.37, p<.001$. Of the two variables entered in this step, only perceived usefulness displayed a significant unique contribution to variance in 
behavioral intention, $b=0.70, t=7.01, p<.001$. In contrast to what was hypothesized, there was no observed moderation effect by agreeableness on the relationship between perceived usefulness and behavioral intention, $\Delta R^{2}<.001, F(1,92)<.001, p>.05$. Thus, the results provide no evidence that the relationship between perceived usefulness and behavioral intention changes at different levels of agreeableness, and Hypothesis $2 \mathrm{~b}$ was not supported.

Hypothesis 3 predicted that openness to experience would moderate the relationship between subjective norms and behavioral intention, such that the relationship will be stronger for those lower in openness to experience. The first step in the model showed that subjective norms and openness to experience, as a set, were related to behavioral intention, $R^{2}=.17, R_{a d j}^{2}=.15, F(2,93)=9.54, p<.001$. Of the two variables entered in this step, only subjective norms displayed a significant unique contribution to variance in behavioral intention, $b=0.45, t=4.31, p<.001$. In contrast to what was hypothesized, there was no observed moderation effect by openness to experience on the relationship between subjective norms and behavioral intention, $\Delta R^{2}=.03, F(1,92)=3.82, p>.05$. Thus, the results provide no evidence that the relationship between subjective norms and behavioral intention changes at different levels of openness to experience, and Hypothesis 3 was not supported.

\section{Control Variables}

In addition to testing the current study's hypotheses, a post hoc analysis was performed to determine whether job control had a confounding effect on relationships between the variables in the current study. To do this, all regression analyses from 
hypothesis testing were performed again with job control included as a control variable. The results showed that while job control was significantly related to behavioral intention, $r(96)=.26, p<.05$, all three predictors of behavioral intention remained significant unique contributors to the variance in behavioral intention, with minimal changes to the size of these contributions. These results suggest job control was not a confounding variable in the current study.

Furthermore, exploratory analyses were performed to control for each demographic variable that could be coded numerically. The analyses showed that when controlling for either voluntariness of use (i.e. whether the use of the IT system at work is mandatory or optional), gender, or work arrangement (i.e. part-time or full-time), the moderation effect by agreeableness on the relationship between perceived ease of use and behavioral intention remained significant. However, the results showed that this moderation effect was not significant when controlling for time of familiarity with the IT system.

Interestingly, one analysis showed a significant moderation effect by openness to experience on the relationship between subjective norms and behavioral intention when controlling for time of familiarity, $\Delta R^{2}=.04, F(1,92)=4.13, p<.05$. The results suggest that, when controlling for time of familiarity with the system, the relationship between subjective norms and behavioral intention changes at different levels of openness to experience, such that the relationship was stronger for those higher in openness to experience, $R^{2}=.20, R_{a d j}^{2}=.16, F(2,45)=5.59, p<.01$. 


\section{Discussion}

Computer technology continues to shape the way organizations operate and conduct business in the modern business environment. Researchers have sought to understand which variables impact the use of IT systems in the workplace, but past studies on technology acceptance (e.g. Devaraj et al., 2008) have left gaps in knowledge that should be addressed. Therefore, the purpose of the current study was to address these gaps in the literature by assessing the effects that different levels of conscientiousness, agreeableness, and openness to experience have on relationships within the technology acceptance model. As a result, the current study provides insight into how individual differences in personality can impact the way an employee perceives and uses new IT systems in the workplace.

\section{Summary of Findings}

The results from the current study supported one of the four hypotheses proposed by the researcher. Hypothesis $2 \mathrm{a}$ was supported through the moderation effect displayed by agreeableness on the relationship between perceived ease of use and behavioral intention. In contrast, the results from hypothesis testing showed no evidence in support of the proposed moderation effects for Hypothesis 1 , Hypothesis $2 \mathrm{~b}$, and Hypothesis 3 . The results of an exploratory post hoc analysis displayed a significant moderation effect by openness to experience on the relationship between subjective norms and behavioral intention when controlling for time of familiarity with the IT system; however, the direction of this effect was inconsistent with the one proposed in Hypothesis 3. Further 
interpretations of these findings are made in the sections to follow, and implications are discussed.

\section{Theoretical Implications}

Results of the correlational analyses support the findings of past research on the TAM (e.g. Venkatesh \& Davis, 2000) in that all relationships between behavioral intention and its supposed predictors (i.e. perceived usefulness, perceived ease of use, and subjective norms) were significant. In further support of the literature (e.g. Devaraj et al., 2008), the relationship between perceived usefulness and perceived ease of use was also significant. Ultimately, the findings from the current study support the notion that positive, linear relationships exist between these constructs.

One finding that conflicts with past literature on the TAM was the strength in the relationship between subjective norms and behavioral intention. A meta-analysis on the TAM performed by Schepers and Wetzels (2007) indicated the relationship between perceived ease of use and behavioral intention was generally stronger than that of subjective norms and behavioral intention across studies; however, results of the current study displayed the opposite, with the relationship between subjective norms and behavioral intention being the stronger of the two relationships. A potential reason for this might stem from the current study being performed more than a decade after the meta-analysis. As computer technology advances and continues to become more integrated into organizations over time, attitudes towards the use of IT systems in the workplace are likely to shift as well. With this in mind, it seems possible that the relationships that perceived ease of use and subjective norms share with behavioral 
intention may also change over time. Considering how IT companies continue to dedicate resources to research on user experience (i.e. a person's perceptions and responses that result from the use of a product; International Organization for Standardization, 2010) to enhance the utility and ease of use of their products, the researcher proposes the relationship between perceived ease of use and behavioral intention will weaken over time. Additionally, the researcher proposes that as organizations become more dependent on IT systems and their use of IT systems becomes more necessary over time, the relationship between subjective norms and behavioral intention will grow stronger.

The current study also adds to the literature through the finding that agreeableness moderated the relationship between perceived ease of use and behavioral intention. As noted by Devaraj et al. (2008), individuals who are highly agreeable tend to be more cooperative when asked to adopt a new IT system, leading these individuals to place more importance on social factors when determining their intention to use the system. Conversely, the moderation effect observed in the current study suggests those lower in agreeableness will place greater importance on non-social factors when deciding whether to use a new IT system in the workplace. This indicates support for the researcher's rationale for Hypothesis $2 \mathrm{a}$, and the observed effect should be studied further to validate these results.

Another way the current study adds to the literature is through the finding that, when controlling for time of familiarity with the IT system, openness to experience moderated the relationship between subjective norms and behavioral intention. As noted by Barrick and Mount (1991), individuals high in openness to experience tend to be non-conforming, 
which was the basis for the rationale made (for Hypothesis 3 ) in the current study in that individuals high in openness to experience would place less importance on social factors (e.g. subjective norms) when deciding whether to use a new IT system. However, in contrast to the hypothesized direction of the effect, the observed moderation effect when time of familiarity with the IT system was held constant suggested these individuals actually placed greater importance on subjective norms when deciding whether to use an IT system. While it is unclear whether the rationale for Hypothesis 3 was flawed, the researcher proposes that these results could be the product of subjective norms towards IT systems becoming more prevalent in the modern workplace. Therefore, the nature and direction of this effect should be investigated further to validate the results of the current study.

\section{Practical Implications}

The results of the current study also provide practical implications that can be applied in organizational settings. Personality testing has been used by organizations to help make hiring decisions since the development of the first modern personality assessment in the early $20^{\text {th }}$ century (Stabile, 2002). Based on the results of the current study, organizations that possess personality data on their workforce can use this information to help them choose between new IT systems and to assess the likelihood that employees will adopt the new system.

Organizations with employees low in agreeableness should strongly consider ease of use when choosing between IT systems, as findings from the current study suggest ease of use is a better predictor of adoption among these individuals. In contrast, results of the 
current study suggest that organizations with employees high in agreeableness, including those with large variance in agreeableness among employees, should consider ways to increase subjective norms as a method of increasing behavioral intention, especially

given that some employees may be high in openness to experience. A potential method of increasing subjective norms towards the use of new IT systems would be to use change management techniques to create a culture of innovation within the organization. One such technique would be to provide training programs on being a change champion to train managers on how to advocate for the use of new IT systems. Once trained, managers could then vocalize their support of using these systems to increase subjective norms at their organization.

\section{Strengths and Limitations}

Strengths. The current study possessed many strengths. One such strength was the sample's level of diversity. The sample was made up of employees in 11 departments from over 16 different industries, and gender group variability was strongly representative of the general population. This allows for the results of the study to be more generalizable across these demographics. Another strength of the current study was that participants were screened to confirm that they met the criteria for inclusion (i.e. that they were currently employed and use a computer at work), which helped ensure participants were members of the sample's target population. Lastly, a third strength was that the results of the current study support and build upon the findings of past studies linking the TAM and personality (e.g. Devaraj et al., 2008). By filling in research gaps 
left behind by these studies, the current study provides a better understanding of the impact that personality traits have on technology acceptance.

Limitations. One limitation of the present study was that participants identified an IT system they were currently using at work for the technology acceptance measure. Because of this, there was not a standard IT system for all participants, which may have impacted the variability in responses for these measures. A second limitation was determined from the descriptive statistics of the variables measured in the current study. All technology acceptance and personality variables displayed averages that were higher than expected and standard deviations that were lower than expected. The high averages and low standard deviations for the technology acceptance variables may have resulted from some participants choosing IT systems that they had been using regularly at work for an extended time period. Additionally, these same qualities exhibited by the personality variables may have been caused by the convenience sampling method used in data collection, as members of the researcher's professional network were not fully representative of the general population.

The poor reliability displayed by the dimensions in the personality measure was another major limitation. This was likely due to the condensing of the IPIP-NEO-120 scale in the current study, and it suggests the researcher's modified version differed from Johnson's (2014) complete measure. Additionally, the poor reliability brings the construct validity of these dimensions into question. A fourth limitation was that the majority of the sample was made up of young adults, leading to a lack of age variability between participants. This brings into question the validity and generalizability of the 
current study, as past studies have found that age had a significant impact on usage behavior and perceptions towards technology (Chung, Park, Wang, Fulk, \& Mclaughlin, 2010; Morris \& Venkatesh, 2000; Arning \& Ziefle, 2009). There is a strong chance that this lack of variability was another product of the convenience sampling method used by the researcher.

\section{Suggestions for Future Research}

Future research linking personality and technology acceptance should be performed using a single, standard IT system for all participants. Ideally, all participants should have an equal amount of exposure to this system, and the sample should be demographically diverse to increase variability between participants. Given the lack of age variability displayed by the sample in the current study, future studies should seek to increase this variability to ensure the sample is more representative of the modern workforce. If higher age variability is obtained, studies should assess the degree to which TAM relationships differ across generations.

Future studies should also use a more reliable measure for personality traits. While the researcher's condensed version was used to avoid issues with low response rates that past studies have related to survey length (Galesic \& Bosnjak, 2009; Kost \& de Rosa, 2018), one method of increasing reliability would be to use the complete version of the IPIP-NEO-120, which has displayed good internal reliability in measuring each of the personality traits in the five-factor model (Johnson, 2014).

Based on the idea that requiring the use of an IT system would naturally impact employees' usage behavior, another suggestion for future studies is to evaluate the effect 
that voluntariness of use may have on TAM relationships. More specifically, studies should test whether the strength of the relationships between behavioral intention and its predictors change depending on whether use of the system is mandatory or optional.

Lastly, future research should also consider assessing individual differences outside of the five-factor model in relation to the TAM. For example, Hofstede's (1980) cultural dimensions could be tested as moderators for TAM relationships. Because of the amount of change involved in adopting a new IT system, cultural dimensions that are linked to attitudes towards change (e.g. uncertainty avoidance; Hill, Loch, Straub, \& El-Sheshai, 1998) should be particularly likely to moderate these relationships. Uncertainty avoidance refers to the degree in which someone feels uncomfortable with ambiguity (Hofstede, 1980). As it is reasonable to assume that adopting a new, unfamiliar IT system can naturally involve a sense of ambiguity, future studies should test whether different levels of uncertainty avoidance affects the strength of the relationship between perceived usefulness and behavioral intention.

\section{Conclusion}

The primary goal of the current study was to address the research gaps left by previous studies on personality and technology acceptance. The findings from this study may help organizations in their selection of IT systems in the future, and the implications of this study provides grounds for future research linking the TAM to individual differences. 


\section{References}

Ajzen, I., \& Fishbein, M. (1980). Understanding attitudes and predicting social behavior. Englewood Cliffs, N.J: Prentice-Hall.

Arning, K. \& Ziefle, M. (2009). Different perspectives on technology acceptance: The role of technology type and age. HCI and Usability for e-Inclusion, 20-41. doi: 10.1007/978-3-642-10308-7_2

Barrick, M. R., \& Mount, M. K. (1991). The big five personality dimensions and job performance: A meta-analysis. Personnel Psych, 44(1), 1-26. doi: 10.1111/j.17446570.1991.tb00688.x

Barrick, M. R., Mount, M. K., \& Judge, T. A. (2001). Personality and performance at the beginning of the new millennium: What do we know and where do we go next? International Journal of Selection and Assessment, 9(2), 9-30. doi: 10.1111/14682389.00160

Behrenbruch, K., Sollner, M., Leimeister, J., \& Schmidt, L. (2013). Understanding diversity - The impact of personality on technology acceptance. HumanComputer Interaction —INTERACT 2013, 306-313. doi: 10.1007/978-3-64240498-6_23

Chung, J. E., Park, N., Wang, H., Fulk, J., \& Mclaughlin, M. (2010). Age differences in perceptions of online community participation among non-users: An extension of the technology acceptance model. Computers in Human Behavior, 26(6), 16741684. doi: 10.1016/j.chb.2010.06.016

Costa. P. T., \& McCrae, R. R. (1992). Revised NEO Personality Inventory (NEO PI-R) and NEO Five-Factor Inventory (NEO-FFI) Professional Manual. Psychological Assessment Resources, Odessa, FL.

Davis, F. D. (1986). A technology acceptance model for empirically testing new end-user information systems: Theory and results (Doctoral dissertation). MIT Sloan School of Management, Cambridge, MA. Retrieved from https://dspace.mit.edu /handle /1721.1/15192

Davis, F., Bagozzi, R., \& Warshaw, P. (1989). User acceptance of computer technology: A comparison of two theoretical models. Management Science, 35, 982-1003. doi: $10.1287 /$ mnsc. 35.8 .982

Davis, F., \& Venkatesh, V. (1996). A critical assessment of potential measurement biases in the technology acceptance model: Three experiments. International Journal of Human-Computer Studies, 45(1), 19-45. doi: 10.1006/ijhc.1996.0040 
Devaraj, Easley, \& Crant, (2008). Research note - How does personality matter? Relating the five-factor model to technology acceptance and use. Information Systems Research, 19, 93-105. doi: 10.1287/isre.1070.0153

Fishbein \& Ajzen. (1975). Belief, attitude, intention and behaviour: An introduction to theory and research. Reading, MA: Addion-Wesley

Galesic, M., \& Bosnjak, M. (2009). Effects of questionnaire length on participation and indicators of response quality in a web survey. Public Opinion Quarterly, 73(2), 349-360. doi: 10.1093/poq/nfp031

Goldberg, L. R. (1993). The structure of phenotypic personality traits. American Psychologist, 48, 26-34. doi: 10.1037/0003-066X.48.1.26

Gosling, S. D., Rentrow, P. J., \& Swann. W. B. (2003). A very brief measure of the BigFive personality domains, Journal of Research in Personality, 37(6), 504-528. doi: 10.1016/S0092-6566(03)00046-1

Hill, C. R., Loch, K. D., Straub, D. W., and El-Sheshai, K. (1998). A qualitative assessment of Arab culture and information technology transfer. Journal of Global Information Management, 6(3), 29-38. Retrieved from https://ideas.repec.org/a/igg/jgim00/v6y1998i3p29-38.html

Hofstede, G. (1980). Culture's consequences: International differences in work-related values. Beverly Hills, CA: Sage.

International Organization for Standardization. (2010). Ergonomics of human-system interaction - Part 210: Human-centered design for interactive systems (ISO Standard No. 9241-210). Retrieved from https://www.iso.org/standard/52075.html

Johnson, J. A. (2014). Measuring thirty facets of the Five Factor Model with a 120-item public domain inventory: Development o the IPIP-NEO-120. Journal of Research in Personality, 51, 78-89. doi: 10.1016/j.jrp.2014.05.003

Karasek, R. (1979). Job demands, job decision latitude, and mental strain: Implications for job redesign. Administrative Science Quarterly, 24(2), 285-308. doi: $10.2307 / 2392498$

Kost, R. G., \& de Rosa, J. C. (2018). Impact of survey length and compensation on validity, reliability, and sample characteristics for Ultrashort-, Short-, and LongResearch Participant Perception Surveys. Journal of clinical and translational science, 2(1), 31-37. doi: 10.1017/cts.2018.18 
McCrae, R. R., \& Costa, P. T. (1997). Conceptions and correlates of openness to experience. Handbook of Personality Psychology 825-847. doi: 10.1016/B978012134645-4/50032-9

Morris, M. G., \& Venkatesh, V. (2000). Age differences in technology adoption decisions: Implications for a changing work force. Personnel Psychology, 53(2), 375-403. doi: 10.1111/j.1744-6570.2000.tb00206.x

Richardson, K., \& Thompson, C. (2012). High tech tethers and work-family conflict: A conservation of resources approach. Engineering Management Research. doi: 10.5539/emr.v1n1p29

Schepers, J., \& Wetzels, M. (2007). A meta-analysis of the technology acceptance model: Investigating subjective norm and moderation effects. Information \& Management,44(1), 90-103. doi: 10.1016/j.im.2006.10.007

Seo, S. (2006). A review and comparison of methods for detecting outliers in univariate data sets. (Unpublished master's thesis). University of Pittsburgh, Pittsburgh, PA.

Sharp (2007). Development, extension, and application: A review of the technology acceptance model. Information Systems Education Journal, 5(9). Retrieved from https://pdfs.semanticscholar.org/4edf/4fc0bcf86d6fd165c22054d093e687fc1 faf.p $\mathrm{df}$

Stabile, S. J. (2002). The use of personality tests as a hiring tool: Is the benefit worth the cost?, University of Pennsylvania Journal of Labor and Employment Law. 4(2), 279-313. Retrieved from https://scholarship.law.upenn.edu/jbl/vol4/iss2/1/

Steptoe, A. (2001). Job control, perceptions of control, and cardiovascular activity: An analysis of ambulatory measures collected over the working day, Journal of psychosomatic research. 50, 57-63. doi: 10.1016/S0022-3999(00)00201-4

Sullivan, M.S. (2012). A study of the relationship between personality types and the acceptance of technical knowledge management systems (TKMS) (Doctoral dissertation). Capella University, Minneapolis, MN. Retrieved from https://realkm.com/wp- content/uploads/2016/07/ Maureen_Sullivan_ Dissertation_2012.pdf

Svendsen, G.B., Johnsen, J.K., Almas-Sorensen, L., \& Vitterso, J. (2013). Personality and technology acceptance: The influence of personality factors on the core constructs of the technology acceptance model. Behavior \& Information Technology, 32(4), 323-334. doi: 10.1080/0144929X.2011.553740 
Taylor, S., \& Todd, P. A. (1995). Assessing IT usage: The role of prior experience. MIS Quarterly, 19(4), 561-570. doi: 10.2307/249633

Venkatesh, V., \& Davis, F. (2000). A theoretical extension of the technology acceptance model: Four longitudinal field studies. Management Science, 46(2), 186-204. doi: 10.1287/mnsc.46.2.186.11926

Venkatesh, V., Morris, M.G., Davis, G.B., \& Davis, F.D. (2003). User acceptance of information technology: Toward a unified view. MIS Quarterly, 27(3), 425-478. doi: $10.2307 / 30036540$ 
Appendix

Survey Items

Technology Acceptance (Davis \& Venkatesh, 1996; Taylor \& Todd, 1995)

Perceived Usefulness

1. Using (insert IT system) improves my job performance.

2. I find (insert IT system) to be useful in my job.

3. Using (insert IT system $)$ increases my productivity at work.

Perceived Ease of Use

1. Interacting with (insert IT system) does not require much of my mental effort.

2. I find it easy to get (insert IT system) to do what I want.

3. I find (insert IT system) to be easy to use.

Subjective Norms

1. People who influence my behavior at work think that I should use (insert IT system).

2. People who are important to me think that I should use (insert IT system).

3. People whose views I respect support the use of (insert IT system).

Behavioral Intention

1. Assuming I have access to (insert IT system), I intend to use it in the future.

2. Given that I have access to (insert IT system), I predict that I will use it in the future.

\section{Personality (Johnson, 2014)}

Openness to Experience

1. I like to get lost in thought.

2. I avoid philosophical discussions. (R)

3. I feel others' emotions.

4. I prefer to stick with things that I know. (R)

5. I see beauty in things that others might not notice.

6. I believe that there is no absolute right and wrong. 


\section{Agreeableness}

1. I take advantage of others. (R)

2. I believe others have good intentions.

3. I get back at others. (R)

4. I am concerned about others.

5. I think highly of myself. (R)

6. I am not interested in other people's problems. (R)

\section{Conscientiousness}

1. I excel in what I do.

2. I jump into things without thinking. (R)

3. I keep my promises.

4. I do just enough work to get by. (R)

5. I waste my time. (R)

6. I like to tidy up.

\section{Job Control (Steptoe, 2001)}

1. I am responsible for deciding how much work gets done in my job.

2. I have freedom to decide what I do in my job.

3. I have control over how I do my job. 